\title{
Effect of Jatrophaand Ethanol Biofuel Blending on Performance of Agricultural Diesel Engine Tractors - Sudan
}

\author{
Mohamed Hassan Dahab ${ }^{1}$, Abdalla Noureldin Osman Kheiry ${ }^{2}$, \\ Tageldeen Saeed Tageldeen Ibramim ${ }^{1}$
}

${ }^{1}$ Department of agricultural Engineering, Faculty of Agriculture, University of Khartoum, Sudan ${ }^{2}$ Department of Agricultural Machinery-College of Agricultural Studies-Sudan University of science and Technology- Khartoum-Sudan A R T I C L E I N F O

Research articles

Received 19 July 2016

Accepted 21 December 2016

Keywords:

Jatropha

Ethanol

Biofuel

Exhaust gases

Blending

Corresponding Author:

E-mail: mhdahabahmed55@yahoo.com

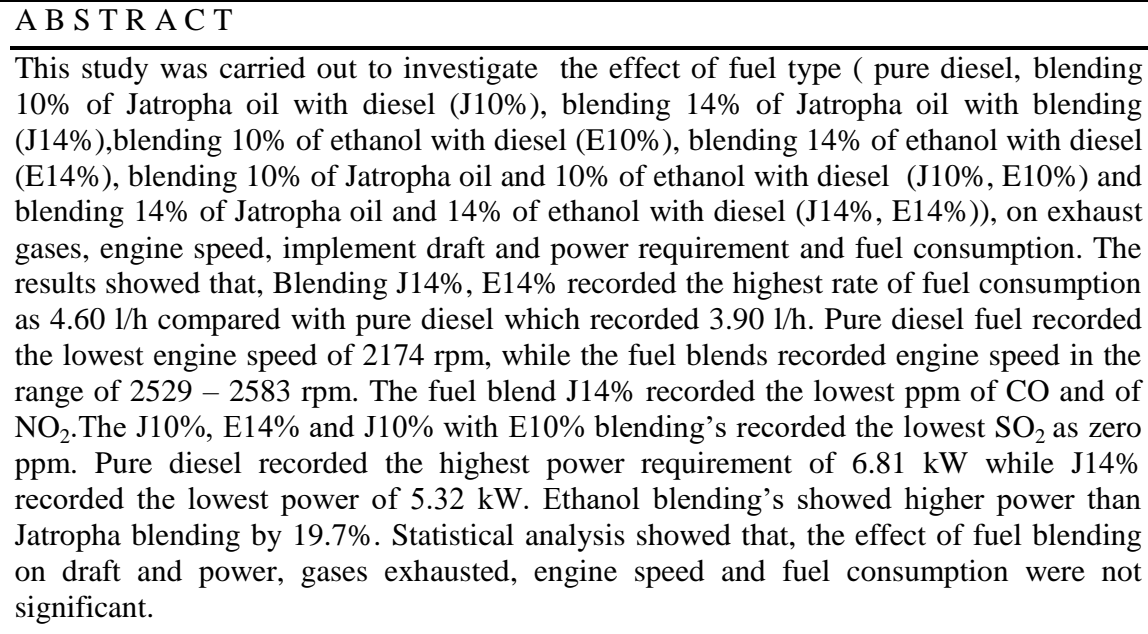
A B S T R A C T

This study was carried out to investigate the effect of fuel type ( pure diesel, blending $10 \%$ of Jatropha oil with diesel (J10\%), blending 14\% of Jatropha oil with blending (J14\%),blending 10\% of ethanol with diesel (E10\%), blending 14\% of ethanol with diesel (E14\%), blending 10\% of Jatropha oil and 10\% of ethanol with diesel (J10\%, E10\%) and blending $14 \%$ of Jatropha oil and 14\% of ethanol with diesel (J14\%, E14\%)), on exhaust gases, engine speed, implement draft and power requirement and fuel consumption. The results showed that, Blending $\mathrm{J} 14 \%$, E14\% recorded the highest rate of fuel consumption as $4.60 \mathrm{l} / \mathrm{h}$ compared with pure diesel which recorded $3.90 \mathrm{l} / \mathrm{h}$. Pure diesel fuel recorded 作 $\mathrm{NO}_{2}$. The $\mathrm{J} 10 \%, \mathrm{E} 14 \%$ and $\mathrm{J} 10 \%$ with $\mathrm{E} 10 \%$ blending's recorded the lowest $\mathrm{SO}_{2}$ as zero ppm. Pure diesel recorded the highest power requirement of $6.81 \mathrm{~kW}$ while $\mathrm{J} 14 \%$ recorded the lowest power of $5.32 \mathrm{~kW}$. Ethanol blending's showed higher power than on draft and power, gases exhausted, engine speed and fuel consumption were not significant.
\end{abstract}

\section{Introduction}

Alternative fuel sources are becoming more important as gases prices raise and petroleum sources dwindle as well as energy crises. The fossil energy resources have many problems like higher prices and raising the emission process of worm gases such as carbon dioxide $\mathrm{CO}_{2}$, Carbon monoxide $\mathrm{CO}$ and other gases. Carbon dioxide $\mathrm{CO}_{2}$ represents one of the most important gases that cause global warming. After approach of fifty (50) to one hundred (100) years, this type of energy resources will diminish. This situation led to the thinking of finding alternative energy sources and put consideration on biomass resources such as bio-Ethanol which is considered friendly to the environment and solution to energy crises and reducing gases emission. The term biofuels cover solid biomass, liquid fuels and various biogases. The main sources of bio-fuels are agricultural crops and agricultural residues, animal waste, and solid municipal waste of biological origin. All these in their raw forms are known as biomass. Bio-fuels include fuel wood, charcoal, livestock manure, biogas, bio hydrogen, bio alcohol. There are many countries producing bio-fuel like Brazil, United States of America, countries of European Union and Sudan recently. Bio-fuels are most commonly used to power vehicles either as a sole fuel or blended with gasoline or other petroleum fuel. It is renewable, less carbon intensive than oil, reduces air pollution hence contributes to mitigate global warming by reducing $\mathrm{CO}_{2}$ emissions.

Jatropha is fast growing crop, begins yielding oil in the second year and continues for forty to fifty years (Yarrapatruni et al., 2009). Optimal yields of oil are obtained from the sixth year. Singh and Padhi (2009) investigated Jatropha oil and its methyl ester to find out their suitability for use as petro-diesel. The study suggested that Jatropha oil can be used as a source of triglycerides in manufacture of biodiesel, cost-effectively. Pramanik (2003) investigated Jatropha oil in a diesel engine. Experimental investigations showed that blending of jatropha methyl esters up to $20 \%$ with diesel for use in an unmodified diesel engine is viable (Chalatlon, et al., 2011, Patil1 et al., 2012). Acceptable thermal efficiencies of the engine were obtained with blends up to J50. Forson et al. (2004) examined the performance of Jatropha oil blends in a diesel engine. The most significant conclusion from the study was that the $\mathbf{J} 2.6$ produced maximum values of brake power and brake thermal efficiency as well as minimum values of specific fuel consumption. Agarwal and Rajamanoharan(2009) and Hazar and Aydin (2010) indicated that the successful use of Jatropha oil is a function of engine type, and percentage of Jatropha oil in the blends. 
The ethanol mixed fuel was found useable on gasoline powered tractors and other engines with correct modifications, this new trend known as blending technique and it becomes a new focus to developed countries as avenue for getting out from nonrenewable and renewable energy sources. In Sudan, due to availability of bio-fuel material represented by ethanol there are many factories started to produce this fuel as secondary product from sugar factories especially in Kenana sugar company and Sennar sugar factory. It was possible to mix bio ethanol with diesel fuel at different percentages and using for agricultural tractors under Sudan condition making it a promising technique and play an important role in solving fuel crisis (Bashir, 2010). In addition to economic return projects, bio-fuels reduce carbon emissions, which share the phenomenon of global warming, climate change and also contribute significantly to the fight against poverty and rural development.

The objective of this study is to evaluate the use of mixed gasoline and biofuel (blending) as a fuel for tractors. The specific objectives of the study are:

To measure implement draft and power requirement, gases exhausted, engine speed (rpm) and fuel consumption.

\section{Materials and Methods}

The experiment was carried out at the demonstration farm of the Faculty of Agriculture, at latitude $15^{\circ} 40^{\prime} \mathrm{N}$ and longitude $32^{\circ} 32^{\prime}$ E. University of Khartoum, Shambat.

The soil of the experimental area was classified as clay loam and the area of the experiment (1.5 fed) was divided into twenty one plots each one equal $300 \mathrm{~m}^{2}$.

Two tractors (Massey Ferguson), were used in the experiment, one as auxiliary for pulling the tested tractor.

A fully mounted disc plough, with three bottoms each $75 \mathrm{~cm}$ in diameter and spaced at $55 \mathrm{~cm}$ was used in the experiment. A hydraulic type Dynamometer, $100 \mathrm{kN}$ was used to measure the draft. Other equipment's used in the experiment were; A glass type, one liter size cylinder for measuring the volume of fuel blended and used in the experiment. Stop watch was used for measuring time required to determine the speed and fuel consumption. A measuring tape, $30 \mathrm{~m}$ long was used for measuring the dimensions and distances to calculate the area of the plots.

Steel chain, Small tanks (gallons) and Pegs were also used in the experiment

- Gas analyzing device: It is a device set to determine the gases emission from engine exhaust, it records the reading in digital, measures gases of $\left(\mathrm{NO}, \mathrm{CO}, \mathrm{SO}_{2}\right.$ and $\mathrm{NO}_{2}$ in ppm ).(Figure 1 )

- Tachometer: It is a digital reading device, operating through a laser radiation hitting into a rotation point to determine the revolution per minute (rpm) (Figure2).

- Fueltypes;a biodiesel made from Jatropha oil was used as blending with pure diesel in different percentage. An ethanol made from molasses, with $96.5 \%$ concentrated was used as blending with pure diesel.
There are some properties comparison between Jatropha oil and standard specifications of diesel oil stated in table (1).

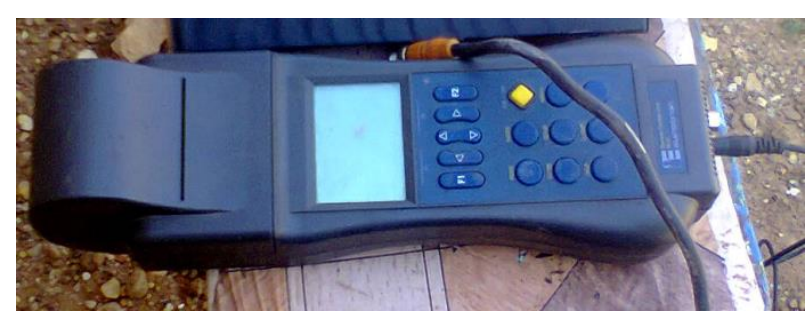

Figure 1 Gas analyzer device.

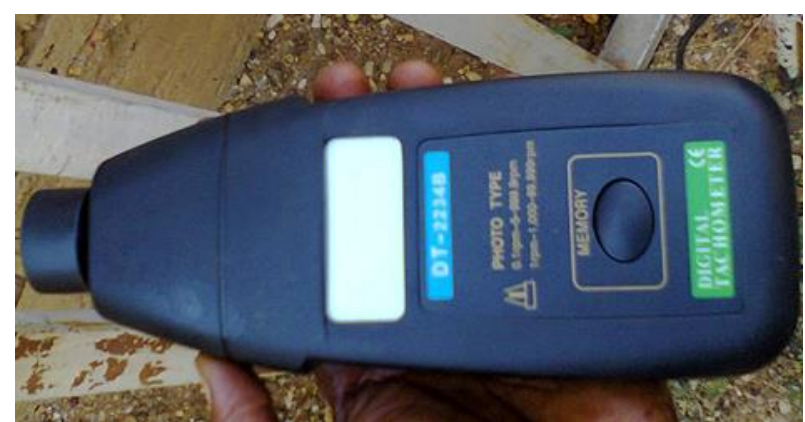

Figure 2 Tachometer

Table 1 Standard specifications of diesel fuel and jatropha oil.

\begin{tabular}{|c|c|c|}
\hline Property & Jatropha oil & Diesel \\
\hline Flash point & $240 / 110^{\circ} \mathrm{C}$ & $50^{\circ} \mathrm{C}$ \\
\hline Carbon residue & 0.64 & 0.15 or less \\
\hline Cetane value & 51.0 & 50.0 up \\
\hline Distillation point $\left({ }^{\circ} \mathrm{C}\right)$ & $295^{\circ} \mathrm{C}$ & $350^{\circ} \mathrm{C}$ \\
\hline Kinematics Viscosity & $50.73 \mathrm{cs}$ & $2.7 \mathrm{cs}$ up \\
\hline Sulphur \% & $0.13 \%$ & $1.2 \%$ or less \\
\hline Calorific value & $9.470 \mathrm{kcal} / \mathrm{kg}$ & $10.170 \mathrm{kcal} / \mathrm{kg}$ \\
\hline Pour point & $8^{\circ} \mathrm{C}$ & $10^{\circ} \mathrm{C}$ \\
\hline Color & 4.0 & 4 or less \\
\hline Viscosity $(\mathrm{cp})\left(30^{\circ} \mathrm{C}\right)$ & $52.6(5.51) 2$ & 3.60 \\
\hline Solidifying Point $\left({ }^{\circ} \mathrm{C}\right)$ & 2.0 & 0.14 \\
\hline
\end{tabular}

Source: (Technological African city 2012)

A completely randomized block design (RCBD) with seven treatments and three replicates was used for the experiment.

The area of experiment (1.5 fed) divided into twenty one plots each plot was $5 \mathrm{~m} \times 60 \mathrm{~m}$. Random distribution of treatments within the blocks was carried out. A space of two meters wide was left for maneuvering of the tractor between plots.

Jatropha oil Preparation and extraction of Bio-diesel

- 25 kilograms of Jatropha seeds was collected from western Sudan (Alabaseya).

- Seeds were crushed by a crusher.

- Extracted oil was collected in a tank (7liters).

- After five days of extracting oil (in order to become stable); the stage of treating by chemical material has begun staring by adding methanol into the oil in ratio of 1:6 respectively. 
- Sodium hydroxide was added in ratio of $50 \mathrm{ml}$ to one litter of jatropha oil.

- Sodium chloride was added $40 \mathrm{ml}$ to 1 litter of jatropha oil. And then the bio-diesel was extracted, the net volume was 3.5liters.

Preparation of bio ethanol: 6 liters of Bio-ethanol concentrated percent of $96 \%$, which was distillated from fermented molass; has been taken from Sudanese company for distillation.

Preparation of mixed fuel: Each fuel type was prepared either pure diesel or mixed diesel with biofuel (jatropha oil and ethanol) in a certain percentage, and putted in small tank with volume of 4 liters.

$400 \mathrm{ml}$ of bio-diesel (jatropha oil) was mixed with 3.6 liter of pure diesel using a measuring cylinder to produce $\mathrm{B} 10 \%$, the total volume of the blending was 4 liters and hence to produce B14\% a volume of $560 \mathrm{ml}$ of bio-diesel (jatropha oil) was added to 3.34 liter of pure diesel also the total volume of the blending was 4 liters.

Mixed diesel \&bio-ethanol: The same way which is done previously was used through used $400 \mathrm{ml}$ of bioethanol with 3.6 liter of pure diesel to produce E10\% and $560 \mathrm{ml}$ of bio-ethanol with 3.44 liter pure diesel to produce E14\% the total volume of each blending was 4 liters.

\section{Treatments}

T1: Pure diesel,

T2: Mixture of $10 \%$ Bio-diesel Jatropha oil with $90 \%$ pure diesel (J10\%),

T3: Mixture of 14\% bio-fuel Jatropha oil with $84 \%$ pure diesel (J14\%),

T4: Mixture of 10\%bio-ethanol with $90 \%$ pure diesel (E10\%),

T5: Mixture of $14 \%$ bio-ethanol with pure diesel (E14\%),

T6: Mixture of $10 \%$ bio diesel, $10 \%$ bio-ethanol with $80 \%$ of pure diesel (J10\%, E10\%)

T7: Mixture of $14 \%$ bio diesel, $14 \%$ bio-ethanol with $72 \%$ of pure diesel (J14\%, E14\%)

Measurement of implement draft was carried out as follows:

The auxiliary tractor (Massey Ferguson 165) and the tested one (Massey Ferguson 440) were linked together through the dynamometer using a steel chain (Figure 3). The auxiliary tractor was first allowed to pull the tested tractor in neutral. The readings of the dynamometer $(\mathrm{KN})$ were recorded at every $20 \mathrm{~m}$ along the $60 \mathrm{~m}$ to collect mean of readings within each plot.

The tested tractor was then loaded with disc plow and operated at constant depth. The readings of dynamometer $(\mathrm{KN})$ were then recorded for the same previous distance (60 $\mathrm{m})$ at every $20 \mathrm{~m}$.

Draft was calculated as follows:

Draft $(\mathrm{KN})=$ pull of tested tractor $($ loaded $)-$ pull of same one (unloaded)

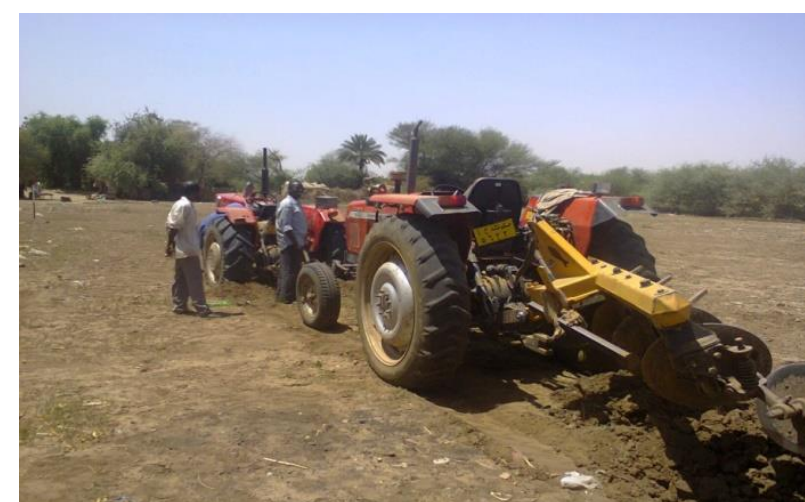

Figure 3 Tested tractor was loaded with disc plow

The power exerted by the tractor on the implement (disc plow) was calculated using this following equation:

$$
\operatorname{Dph} p=\frac{D \times S}{C f}
$$

Where:

$$
\begin{array}{ll}
\text { Dbhp } & \text { : Drawbar power }(\mathrm{kW}) \\
\mathrm{D} & : \text { Implement draft }(\mathrm{kN} \\
\mathrm{S} & : \text { Forward speed }(\mathrm{km} / \mathrm{h}) \text {. } \\
\mathrm{C} f & : \text { Correction factor }(3.6)
\end{array}
$$

The fuel consumption rate was determined as follows:

- The tractor started working the plot with known volume of fuel.

- The tank was refilled after finishing the plot.

- The volume of fuel used to refill the tank was recorded in $\mathrm{ml}$.

- The time taken to finish the plot was recorded and the width done by implement also recorded.

- Fuel consumption rates were calculated in liter per hour and liter per Fadden as follows:

$F C\left(\frac{l}{h r}\right)=\frac{\text { reading cylinder }(\mathrm{ml}) \times 0.06}{\text { time required to cover the area }(\mathrm{min})}$

Where:

0.06: Factor to convert $(\mathrm{ml} / \mathrm{min})$ to $(1 / \mathrm{h})$.

$$
F C\left(\frac{l}{f d}\right)=\frac{\text { reading cylinder }(m l) \times 10}{\text { covered area }\left(m^{2}\right)}
$$

Where:

10: Factor to convert $\left(\mathrm{ml} / \mathrm{m}^{2}\right)$ to $(1 / \mathrm{fd})$.

Exhaust gases were determined using gas analyzer device, the readings was taken every 30 seconds, by:

- Putting a metal pipe inside exhaust muffler this pipe connected to the measurement device by plastic tube.

- After a 30 second the device illustrate the quantities of gases on a screen in digital.

- Gas analyzer device must be resetting before every use a new type of fuel by calibrating it in zero number. 
The engine speed was measured by putting reflecting body on rotating pulley at the end of crank shaft. Meanwhile the tractor engine was operating in normal throttle.

- Hitting a laser radiation by the tachometer into that rotating pulley.

- A digital record of speed (revolution per minute) will appear on the device screen.

\section{Results and Discussions}

In order to determine the effect of different type of fuel on experiment parameters the variance analysis of variance is given in Table 2

Table 2 Statistical description of variation for all observed parameters affected by different fuel types:

\begin{tabular}{l|ccc}
\hline Observed Parameters & M. S & P. Value & F. value \\
\hline Power & 0.501 & 0.082 & 2.52 \\
Fuel Consumption & 0.58 & 0.914 & 0.32 \\
Draft & 0.328 & 0.275 & 1.45 \\
\hline
\end{tabular}

Effect of Fuel Type on Power

Statistical analysis showed that, the effect of fuel type on power is not significant at $(\mathrm{P} \leq 0.05)$, Table 2 . It was observed that the fuel type of pure diesel; recorded the highest power among other types of $6.81 \mathrm{~kW}$, and the lowest one was $\mathrm{J} 14 \%$ of $5.32 \mathrm{~kW}$ (Figure 4).

This might be due to a unique chemical construction of the diesel fuel compared to the blending which probably some changes in their chemical constructions have been done.

There was a considerable decrease in power produced by Jatropha blend, and hence it take to decreasing as Jatropha oil proportion increase in the blend comparing with pure diesel, this due to lower thermal efficiencies of the blends and the jatropha oil than pure diesel. This result is confirmed with (Pramanik, 2003) who found the drop in thermal efficiency with increase in proportion of vegetable oil on the blending due to their high viscosity and poor volatility.

Also there was a reduction in power produced by Ethanol blend due to increased

leakage in the fuel injection pump with the lower viscosity fuels, this result is in accordance with the findings of Adam (1995) who observed the high power on diesel fuel comparing with blends of ethanol through using a gasoline engine, and Alan et al. (2005) who reported a 5\% drop in maximum fuel delivery when evaluating a $30 \%$ ethanol-diesel blend in a tractor engine.

\section{Effect of Fuel Type on Fuel Consumption:}

It was observed that the fuel type blended with ethanol recorded the highest rate of fuel consumption while E14\% and $\mathrm{J} 10 \%$ recorded the lowest fuel consumption 3.59 and $3.46 \mathrm{~L} / \mathrm{h}$ respectively (Figure 5). The differences in fuel consumption between different fuel types were statistically not significant (Table 2).

It was observed that the fuel consumption increases as the percentage of ethanol increases when using the blends than that of the diesel. This is may be due to the drop in the calorific value of the blends which were included ethanol as compared to that of diesel. However fuel consumption of diesel approaches as same as Jatropha bio-diesel blends; this is might be due to relatively same of their chemical and physical properties. This result confirmed with the findings of Sami (2011), who made comparisons of chemical and physical properties between Jatropha bio-diesel and diesel.

\section{Effect of Fuel Type on Engine Speed}

It was observed that pure diesel fuel recorded the lowest rpm (2174), while the blends recorded higher engine speed except $\mathrm{J} 14 \%$ which recorded (2258 rpm). (Figure 6).

The standard engine speed according to Nebraska tests is $2000 \mathrm{rpm}$; so that it clear diesel was in line of Nebraska standard but the blending fuels recorded higher speed. The statistical analysis in Table 2 shows that there are no significant differences $(\mathrm{P} \leq 0.05)$ in engine speed as affected by different fuel types.

Jatropha blends fuel type are recorded engine speed close to the pure diesel, this may be due to the approximately same of some chemical properties of diesel and Jatropha oil, while the Ethanol blends fuel type are recorded higher engine speed than pure diesel record due to different properties between pure diesel and ethanol such a blend stability, viscosity and lubricity, energy content and Cetane number, this result is in accordance with the findings of Alan et al (2005) who recorded factors affected on blended fuel properties when adding ethanol to diesel fuel.

\section{Effect of Fuel Type on Gases Emission}

The results showed that the highest $\mathrm{CO}$ was recorded by $(\mathrm{J} 10 \%)$ and $(\mathrm{J} 10 \% \& \mathrm{E} 10 \%) ; 274$ and $271 \mathrm{ppm}$ respectively, while the lowest one was recorded by (J14\%) 200ppm. (Table 3) It was observed that Jatropha blending had high CO. This result is confirmed with Sami (2011) who was record the higher carbon residue on Jatropha oil than that on diesel.

There was substantially increasing in $\mathrm{CO}$ on the blending comparing with pure diesel, due to a number of factors, these factors may be; exhaust control technology, age of the tractor, maintenance history, test procedure, and test conditions. This result is in same line with Alan (2005) who recommended the necessity of extensive testing of these fuel types (blending) in older and late model diesel engines, in order to accurately assess performance.

$(\mathrm{J} 14 \%)$ and $(\mathrm{J} 14 \% \& \mathrm{E} 14 \%)$ treatments were recorded the highest $\mathrm{SO}_{2}$ of $3 \mathrm{ppm}$, while the pure diesel and (E10\%) treatments recorded 1ppm compared to $(\mathrm{J} 10 \%)$. (E14\%) and $(\mathrm{J} 10 \% \& \mathrm{E} 10 \%)$ treatments recorded zero ppm.

The chemical and physical analysis of Jatropha biodiesel, bio-ethanol and diesel showed that sulphur on Jatropha oil was $0.13 \%$, as same as ethanol and for diesel was $1.2 \%$. This was the reason which interpreted the relative highly of $\mathrm{SO}_{2}$ on diesel compared to bio-diesel blends. This result is confirmed with findings of technical African city which was made these analyses. Ethanol- 
diesel fuel blending showed the lowest records among all treatments especially when ethanol portion increased in the blend comparing with pure diesel. There were decreases and increases in $\mathrm{SO}_{2}$ emissions dependent on speed and load of the engine. The results showed that the highest NO recorded by E14\% treatment (109ppm) while the lowest was recorded by pure diesel (71ppm). It was observed that Ethanol blending fuel type were higher record of NO than Jatropha blending recorded by $12 \%$ but the pure diesel was still the lowest record. This is due to high quantity of (NO) on bio-Ethanol. This result is confirmed by the findings of Areeg (2012).

It can be observed that the $\mathrm{J} 10 \%$ treatment recorded the highest quantity of $\mathrm{NO}_{2}(7 \mathrm{ppm})$, which was less than the diesel alone by 1ppm, E14\% and $\mathrm{J} 10 \%$ \& $10 \%$ recorded 4 ppm, E10\% and $\mathrm{J} 14 \% \& \mathrm{E} 14 \%$ recorded 3ppm and $\mathrm{J} 14 \%$ recorded the lowest $\mathrm{NO}_{2}$ of zero ppm.

Higher nitrogen dioxide on diesel fuel compared to bio fuel blends especially on bio-ethanol blends have also been reported by Adam (1995).

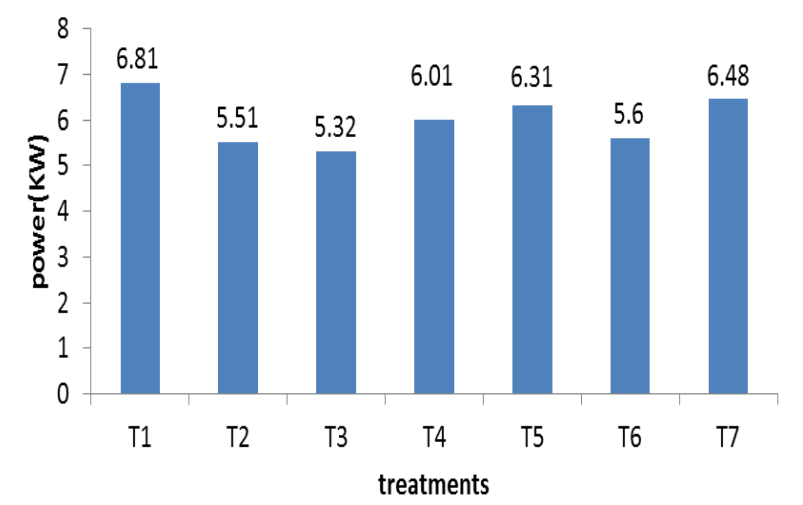

Figure 4 Effect of fuel type on power (KW).

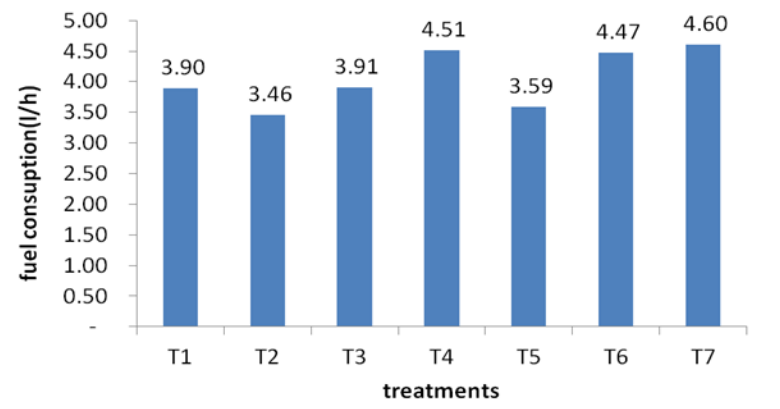

Figure 5 Effect of fuel types on fuel consumption (1/h).

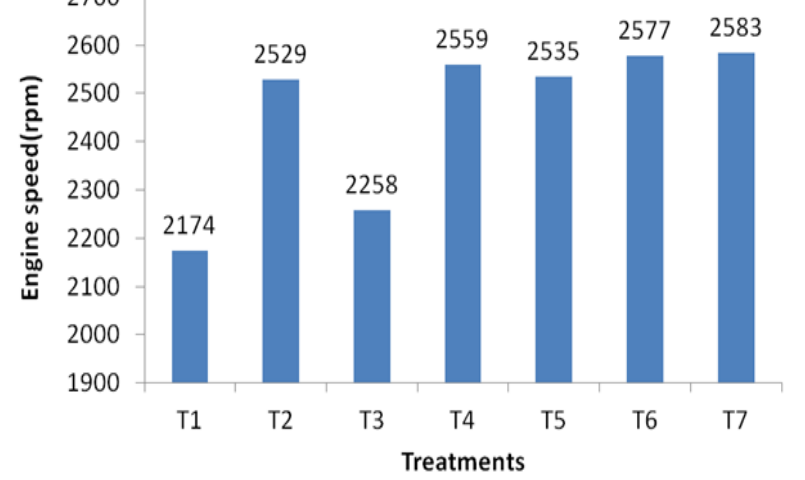

Figure 6 Effect of fuel type on engine speed (rpm).
Table 3 Effect of treatments on gases measured (ppm)

\begin{tabular}{l|ccccccc}
\hline Fuel type & T1 & T2 & T3 & T4 & T5 & T6 & T7 \\
\hline $\mathrm{CO}$ & 243 & 274 & 200 & 239 & 249 & 271 & 255 \\
$\mathrm{NO}_{2}$ & 6 & 7 & 0 & 3 & 4 & 4 & 3 \\
$\mathrm{SO}_{2}$ & 1 & 0 & 3 & 1 & 0 & 0 & 3 \\
$\mathrm{NO}$ & 71 & 96 & 97 & 97 & 109 & 96 & 92 \\
\hline
\end{tabular}

T1: Pure diesel, T2: Blending (J10\%), T3: Blending (J14\%), T4: Blending (E10\%), T5: Blending (E14\%), T6: Blending (J10\%, E10\%), $\mathrm{T} 7$ : Blending $(\mathrm{J} 14 \%, \mathrm{E} 14 \%), \mathrm{E}=$ Ethanol, $\mathrm{J}=$ Jatropha oil.

\section{Conclusions}

From the results of this study the following conclusion can be drawn:

- Diesel fuel recorded the highest power recorded compare the other types of fuel while the ethanol blending, recorded the highest rate of fuel consumption.

- Diesel was recorded the lowest engine speed in rpm.

- $\mathrm{J} 14 \%$ treatment recorded the lowest CO while the three types of blended fuels gave the lowest quantities of $\mathrm{SO}_{2}$ compared with pure diesel.

- From the experimental results obtained, Jatropha biodiesel is found to be a promising alternative fuel for economic running of compression ignition engines.

\section{References}

Adam BA. 1995. Performance of Gasoline Engine using gasoline /ethanol Blends, M.Sc. thesis, University of Khartoum, faculty of engineering and Architecture, pp.36-38.

Agarwal AK, Rajamanoharan K. 2009. Experimental investigations of performance and emissions of Karanja oil and its blends in a single cylinder agricultural diesel engine. Appl. Energy, 86(1): 106-112.

Alan C. Hansen QZ, Peter WLL. 2005. Ethanol-diesel fuel blends-a review, Review Paper, Department of Agricultural and Biological Engineering, University of Illinois, USA.

Areeg MT. 2012. Energy research center,personal contact, Khartoum, Sudan.

Bashir AA 2010. Biofuel Production and Potential in Sudan, University Of Khartoum, Institute of Environmental Studies.

Kenana Sugar Company. 2012 Production of sugar factories during year 2011.Sudan, White Nile State, personal contacts.

Pramanik K. 2003. Properties and use of jatropha curcas oil and diesel fuel blends in compression ignition engine. Review Paper, Renewable Energy, vol28, Iss 2: 239-248.

Sami YA. 2011. The comparison of properties of Jatropha oil and standard specifications of diesel oil, report, African technical city, Khartoum, Sudan.

Singh RK, Padhi SK. 2009. Characterization of Jatropha oil for preparation of biodiesel. Nat. Prod. Radiance, 8(2): 127-132.

Yarrapathuni VHR, Ram Voleti RS, Pereddy NR, Alluru VSR. 2009. Jatropha oil methyl ester and its blends used as an alternative fuel in diesel engine. Therm. Sci., 13(3): 207-17.

Hazar H, Aydin H. 2010. Performance and emission evaluation of a CI engine fueled with preheated raw rapeseed oil (RRO)-diesel blends. Appl. Energy, 87(3): 786-790.

Forson FK, Oduro EK, Hammond-Donkoh E. 2004. Performance of Jatropha oil blends in a diesel engine. Renew. Energ. 29(7): $1135-45$. 